\title{
Simulated pain and cervical motion in patients with chronic disorders of the cervical spine
}

\author{
Zeevi Dvir PhD ${ }^{1}$, Noga Gal-Eshel MSc ${ }^{1}$, Boaz Shamir MSc ${ }^{1}$, Evgeny Pevzner MD², \\ Chava Peretz $\mathrm{PhD}^{1}$, Nachshon Knoller $\mathrm{MD}^{3}$
}

\begin{abstract}
Z Dvir, N Gal-Eshel, B Shamir, E Pevzner, C Peretz, N Knoller. Simulated pain and cervical motion in patients with chronic disorders of the cervical spine. Pain Res Manage 2004;9(3):131-136.
\end{abstract}

The primary objective of the present study was to determine how simulated severe cervical pain affects cervical motion in patients suffering from two distinct chronic cervical disorders: whiplash $(\mathrm{n}=25)$ and degenerative changes $(n=25)$. The second objective was to derive an index that would allow the differentiation of maximal from submaximal performances of cervical range of motion. Patients first performed maximal movement of the head (maximal effort) in each of the six primary directions and then repeated the test as if they were suffering from a much more intense level of pain (submaximal effort). All measurements were repeated within four to seven days. In both groups, there was significant compression of cervical motion during the submaximal effort. This compression was also highly stable on a test-retest basis. In both groups, a significantly higher average coefficient of variation was associated with the imagined pain and it was significantly different between the two clinical groups. In the whiplash group, a logistic regression model allowed the derivation of coefficient of variation-based cutoff scores that might, at selected levels of probability and an individual level, identify chronic whiplash patients who intentionally magnify their motion restriction using pain as a cue. However, the relatively small and very stable compression of cervical motion under pain simulation supports the view that the likelihood that chronic whiplash patients are magnifying their restriction of cervical range of motion using pain as a cue is very low.

Key Words: Motion; Pain; Simulation; Whiplash

\section{La simulation de la douleur et le mouvement cervical chez des patients souffrant de troubles chroniques de la colonne cervicale}

La présente étude visait à déterminer à quel point la simulation d'une douleur cervicale grave nuit au mouvement cervical des patients atteints de deux troubles cervicaux chroniques : le coup de fouet cervical $(n=25)$ et les changements dégénératifs $(\mathrm{n}=25)$. Le deuxième objectif consistait à dériver un indice qui permettrait de différencier la performance maximale de la performance sous-maximale d'amplitude des mouvements cervicaux. Les patients ont d'abord exécuté le mouvement maximal de leur tête (effort maximal) dans chacune des six directions primaires et ont repris le test comme s'ils souffraient d'une douleur beaucoup plus intense (effort sous-maximal). Toutes les mesures ont été reprises au bout de quatre à sept jours. Dans les deux groupes, on remarquait une compression importante du mouvement cervical pendant un effort sous-maximal. Cette compression était également très stable d'après un test-retest. Dans les deux groupes, un coefficient de variation beaucoup plus élevé s'associait à la douleur imaginée et divergeait de manière significative entre les deux groupes cliniques. Dans le groupe clinique ayant souffert d'un coup de fouet cervical, un modèle de régression logistique a permis de dériver des coefficients seuils de variation qui pourraient, à des taux sélectionnés de probabilité et sur une base individuelle, permettre de repérer les patients ayant souffert d'un coup de fouet cervical entraînant des douleurs chroniques qui limitent intentionnellement leurs mouvements cervicaux selon les douleurs qu'ils ressentent. Cependant, la compression relativement faible et très stable du mouvement cervical d'après une simulation de la douleur étaye que la probabilité selon laquelle les patients ayant souffert d'un coup de fouet cervical entraînant des douleurs chroniques limitent intentionnellement leurs mouvements cervicaux selon les douleurs qu'ils ressentent soit très faible.
$\mathrm{T}$ he rating of impairment resulting from whiplash injury is widely regarded as a complicated task when the severity of the symptoms/signs do not exceed grade II of the Quebec Task Force classification system (1). This specific grade means that the injury involves predominantly soft tissue components and is apparently free of clearly discernible neurological or bony components. A typical patient relates to the existence of one or more of the following associated disorders: neck pain, restriction of cervical range of motion (CROM), dizziness, temporomandibular dysfunction and/or various cognitive and psychological deficits.

Although most of these disorders can be measured instrumentally, the determination of their severity requires full patient cooperation in performing the tests. If this is not the case, the findings cannot serve as a valid basis for clinical decisions. Hence, irrespective of the precision and reproducibility of the relevant measurements, it is critical that a mechanism enabling clinicians to accept or reject a subjective complaint be available. However, research concerning patient cooperation in performing such tests has received conspicuously little scientific attention. This void coincides with, and may have even invited, implicit or explicit doubts regarding the existence of these disorders or their severity $(2-4)$ while sparking fierce debates among professionals $(5,6)$. Because $19 \%$ to $60 \%$ of whiplash patients eventually continue into the chronic disabling stage (7), the far reaching implications of this dearth of research cannot be exaggerated.

\footnotetext{
${ }^{1}$ Department of Physical Therapy, Sackler Faculty of Medicine, Tel Aviv University, Tel Aviv; ${ }^{2}$ Spine Surgery Unit, Department of Orthopedic Surgery, Sappir Medical Center, Kfar Saba; ${ }^{3}$ Department of Neurosurgery, Sheba Medical Center, Sackler Faculty of Medicine,

Tel Aviv University, Tel Aviv, Israel

Correspondence: Dr Zeevi Dvir, Department of Physical Therapy, Sackler Faculty of Medicine, Tel Aviv University, Israel 69978.

Telephone 00972-3-640-5429, fax 00972-3-640-9923, e-mail zdvir@post.tau.ac.il
} 
In an effort to examine whiplash-related symptom magnification, psychological attributes and pain responses were compared between students asked to simulate chronic cervical pain (to ensure compensation) with those derived from whiplash patients (8). The students scored significantly higher on the Symptom Checklist-90 Revised personality questionnaire and the Visual Analogue Scale than did the patients, but the McGill pain scores were similar for both groups. The authors concluded that it was very difficult for a nongenuine subject to fake the typical psychological profile of a whiplash patient. However, in the absence of specificity and sensitivity scores, cut-off values could not be established. Consequently, the certainty of the sincerity of a claim could not be determined based on the psychological manifestations of whiplash injury. In a later study (9), the kinematics of head motion in patients with neck pain following whiplash were compared with those of normal subjects who received an explanation regarding whiplash symptomatology and then simulated painful neck movement. All participants performed slow free and tracking rotations while head kinematics was recorded and analyzed. Significant differences in amplitude, frequency, symmetry of motion and harmonic factors were observed between the groups, particularly the inability of normal subjects to simulate and reproduce distinct pain patterns convincingly. In addition, no differentiation rule was defined between the groups. Interestingly, when normal subjects were asked to fully cooperate in performing CROM (maximal effort) and to then feign restriction of CROM (submaximal effort) based on a fictitious neck injury, head motion during feigning was reduced by approximately $50 \%$ across all movement planes (10). Moreover, using the coefficient of variation, a consistency index which relates to a set of repetitive motions, resulted in the determination of a cut-off value that effectively separated the two levels of effort. These findings were repeated in a recent study (11) with normal subjects where the feigning of CROM using severe pain as a cue resulted in a significantly sharper reduction of scores compared with the feigning of CROM using a fictitious financial incentive.

However, to the best of our knowledge, no study to date has looked into submaximal effort in whiplash patients, specifically with respect to magnifying the restriction of CROM. Our particular interest in this symptom reflects the fact that it is the best estimator of handicap one-year following injury (12). Moreover, CROM is the basis for the determination of impairment using the range of motion method advocated by the American Medical Association's Guides to the Evaluation of Permanent Impairment (13). In addition, the availability of dedicated systems for measuring CROM in all dimensions of head motion renders the evaluation of this specific disorder highly accurate and reproducible. Because asking patients to feign effort for financial gain is ethically unacceptable, simulated intense pain was chosen as the cue. It is worth noting that such a paradigm has already been used to test patients with chronic low back pain (14). Therefore, the two primary objectives of the present study were: to determine how simulated severe cervical pain affects CROM in patients with neck disorders, and to establish, under these circumstances, a quantitative parameter capable of differentiating maximal and submaximal levels of effort. To obtain a comprehensive perspective, the results from whiplash patients were compared with those derived from patients suffering from degenerative changes in the cervical spine where no external financial gain was apparent.

\section{Patients}

\section{METHOD}

Twenty-five consecutive patients, 13 women and 12 men, of a similar age range (19 to 55 years, mean [SD]: 37.1 [9.9] years), injured in whiplash-type accidents were included in the study. All patients were conservatively treated and were seeking further medical help because pain or other disorders did not subside. Patients were included in the study if it had been at least six months since the accident, the severity of injury was classified as grade I to II according to the Quebec Task Force definition, they had no previous history of neck trauma or pathology, and had no other injury relating to a previous motor vehicle accident. Pregnant women were not included in the study. The group of patients suffering from cervical degenerative changes (CDC) was comprised of 25 consecutive patients, 11 women and 14 men aged 28 to 70 years (mean [SD]: 48.1 [16.2] years). The inclusion criteria for the CDC groups consisted of positive spinal cord pressure as revealed by magnetic resonance imaging, degenerative changes in the cervical spinal column involving no more than three levels and no prior operative history in the region. Of the 25 patients, disc pathology was indicated in 19 patients (13 cases were associated with disc protrusion), five patients presented with osteophyte pathology and one patient presented with a meningioma. In addition, it had been at least one year since the onset of their symptoms. Patients in the CDC group were candidates for anterior cervical decompression and fusion. All 50 patients signed an informed consent form. The study was endorsed by the Institutional Review Boards of Tel Aviv University and the Sheba Medical Center.

\section{Instrumentation}

Measurement of cervical motion in the three principal planes was performed using the Zebris CMS 70P system (Zebris Medizintechnik, Germany) which is based on triangulation of ultrasound waves emitted by special sensors attached to the head and chest (15).

\section{Measurement procedure}

All measurements were performed twice with an intersession difference of four to seven days. Before the first testing session (test 1), demographic and clinical data were recorded. Patients were also asked to fill in a neck disability questionnaire which yielded the Neck Disability Index (NDI) (16). The questionnaire consisted of 10 subscales, including three which related to cervical pain, headache and work capacity. Each subscale was rated according to a six-point scale ( 0 to 5 ), where 5 corresponds to the most severe pain/limitation. The pain subscale consisted of: 0 - I have no pain at the moment; 1 - the pain is very mild at the moment; 2 - the pain is moderate at the moment; 3 - the pain is fairly severe at the moment; 4 - the pain is very severe at the moment; and 5 - the pain is the worst imaginable at the moment. Thus, although the maximal possible NDI score is 50 , the following classification is used in practice: 0 to 4 - no disability; 5 to 14 - light disability; 15 to 24 - moderate disability; 25 to 34 - severe disability; and NDI greater than 34 - full disability.

For CROM measurements performed in the seated position, the 'zero' (reference) position of the head was defined as the anatomical position (vertically upright without rotation), subjectively 
TABLE 1

Frequency of patients according to the Neck Disability Index (NDI) and pain categories

\begin{tabular}{lccccc}
\hline NDI categories & W (n) & CDC $(\mathbf{n})$ & Pain intensity & W (n) & CDC (n) \\
\hline $\mathbf{0 - 4}$ & 1 & 0 & $\mathbf{0}$ & 0 & 0 \\
$\mathbf{4 - 1 4}$ & 4 & 5 & $\mathbf{1}$ & 1 & 5 \\
$\mathbf{1 5 - 2 4}$ & 8 & 4 & $\mathbf{2}$ & 7 & 5 \\
$\mathbf{2 5 - 3 4}$ & 11 & 11 & $\mathbf{3}$ & 7 & 7 \\
$\mathbf{3 4}$ & 1 & 5 & $\mathbf{4}$ & 5 & 4 \\
& & & $\mathbf{5}$ & 5 & 4 \\
\hline
\end{tabular}

CDC Chronic degenerative changes; $W$ Whiplash

determined by each subject. Cervical motion was measured with respect to each primary direction (PD) of motion, namely, flexion, extension, right and left rotation, and right and left lateral flexion using reciprocal movements (17). Starting with the standard test, patients were instructed to perform the motions at a comfortable, self-selected pace and proceed with the head motion until it provoked pain. This sequence was repeated three consecutive times. The order of testing consisted of rotation, lateral flexion, flexion and extension. Following a break of $15 \mathrm{~min}$, the following instruction was read to the patient, "imagine that you are now suffering from pain which is much more intense than what you are actually experiencing and perform cervical motion as if under this higher level of pain". The same CROM measurement protocol was applied.

\section{Data analysis}

All data are presented as mean (SD). Descriptive and inferential (mixed effect model) statistics were performed using the SAS software (SAS Institute Inc, USA).

\section{NDI and pain scores}

\section{RESULTS}

The distributions of both groups were quite similar with respect to both the global and specific scales (Table 1). However, the CDC group presented with a slightly higher severity in NDI score and lower severity in pain scores than the whiplash group.

\section{Pain and CROM}

In the whiplash group, the correlation between the severity of pain derived from the NDI questionnaire and the PD-based CROM was very low (ranging from -0.04 to -0.24 ). Similarly, the global NDI score correlated poorly with CROM (ranging from -0.02 and -0.28 ). Comparable correlation coefficients were obtained from CDC patients: -0.02 to -0.21 for the pain-CROM relationship and -0.08 to -0.15 for the NDI-CROM relationship.

\section{Reproducibility of CROM}

The test-retest reproducibility was assessed using an intraclass correlation coefficient $(3, \mathrm{k})$ model where each score was the average of the three consecutive measurements. Excellent intraclass correlation coefficients were obtained from whiplash patients for the maximal and submaximal effort, ranging from 0.89 to 0.92 and 0.87 to 0.93 , respectively. The corresponding results from the CDC group were equally high, ranging from 0.80 to 0.95 (maximal effort) and 0.81 to 0.94 (submaximal effort). A detailed reproducibility analysis will be published elsewhere.

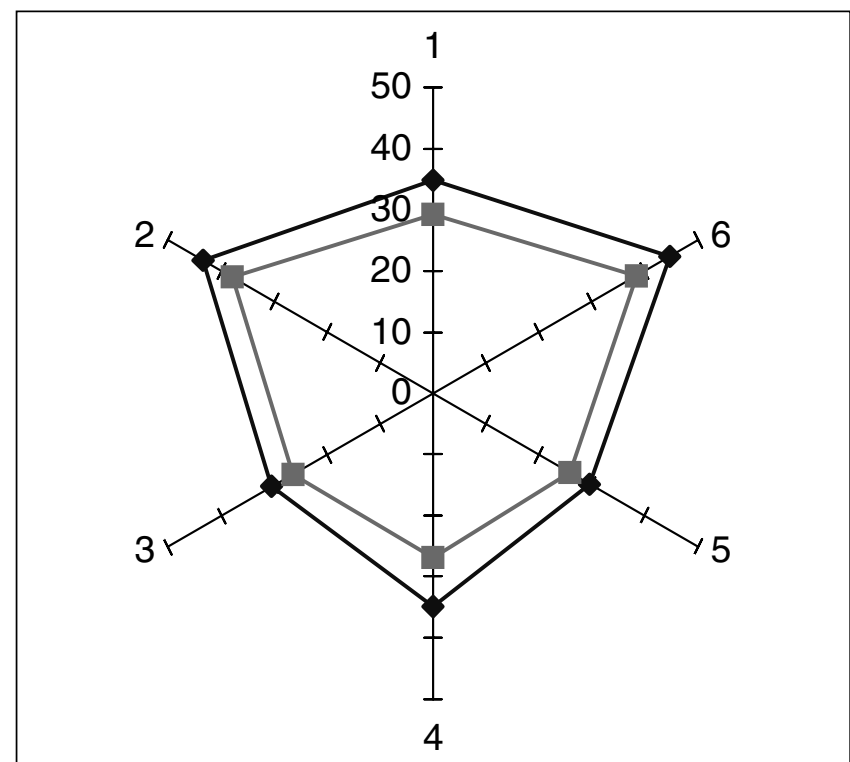

Figure 1) Hexagonal representation of the mean cervical range of motion scores in whiplash patients in maximal effort (outer hexagon) versus simulated pain (submaximal effort) (inner hexagon) in test 1 . The rays radiating from the point of intersection $(0)$ are scaled to degree. The following numbers correspond to the primary directions: 1 - flexion; 2 - right rotation; 3 - right lateral flexion; 4 - extension, 5 - left lateral flexion; and 6 - left rotation

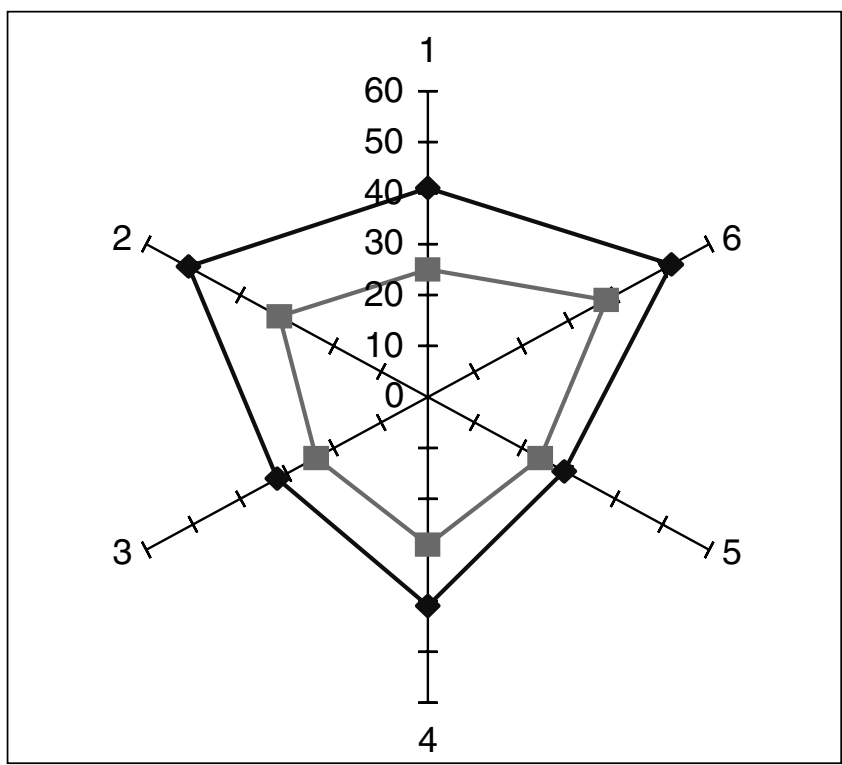

Figure 2) Hexagonal representation of the mean cervical range of motion scores in patients with chronic degenerative changes in maximal effort (outer hexagon) versus simulated pain (submaximal effort) (inner hexagon) in test 1 . The rays radiating from the point of intersection $(0)$ are scaled to degree. The following numbers correspond to the primary directions: 1 - flexion; 2 -right rotation; 3 -right lateral flexion; 4 -extension; 5 - left lateral flexion; and 6 - left rotation

CROMs in maximal versus submaximal effort

The CROMs are presented in Figures 1 and 2. Because the general features remained the same during the second testing session (test 2), the findings from this session are not shown. Two mixed-effects models, where the absolute CROM was the 


\section{TABLE 2}

Reduction of cervical range of motion (CROM) due to submaximal effort in whiplash and chronic degenerative changes (CDC) groups

\begin{tabular}{|c|c|c|c|c|}
\hline \multirow[b]{3}{*}{ PD } & \multicolumn{4}{|c|}{ (CROM in submaximal effort) / (CROM in maximal effort) } \\
\hline & \multicolumn{2}{|c|}{ Whiplash } & \multicolumn{2}{|c|}{ CDC } \\
\hline & Test 1 & Test 2 & Test 1 & Test 2 \\
\hline Extension & $0.73(0.25)$ & $0.77(0.24)$ & $0.74(0.51)$ & $0.74(0.52)$ \\
\hline Flexion & $0.84(0.37)$ & $0.87(0.27)$ & $0.63(0.29)$ & $0.71(0.36)$ \\
\hline Left rotation & $0.85(0.22)$ & $0.86(0.25)$ & $0.76(0.48)$ & $0.63(0.32)$ \\
\hline Right rotation & $0.86(0.25)$ & $0.87(0.20)$ & $0.63(0.33)$ & $0.76(0.50)$ \\
\hline \multicolumn{5}{|l|}{ Left lateral } \\
\hline flexion & $0.87(0.21)$ & $0.88(0.21)$ & $0.89(0.65)$ & $0.80(0.46)$ \\
\hline \multicolumn{5}{|l|}{ Right lateral } \\
\hline flexion & $0.88(0.20)$ & $0.88(0.23)$ & $0.72(0.26)$ & $0.71(0.38)$ \\
\hline
\end{tabular}

All data presented as mean (SD). PD Primary direction

\section{TABLE 3}

Coefficient of variation scores during maximal (max) and submaximal (sub) effort for the whiplash group

\begin{tabular}{lccccc}
\hline \multirow{2}{*}{ Primary direction } & \multicolumn{2}{c}{ Test I (\%) } & & \multicolumn{2}{c}{ Test 2 (\%) } \\
\cline { 2 - 3 } \cline { 6 - 7 } & Max & Sub & & Max & Sub \\
\hline Extension & $9.4(8.6)$ & $9.1(9.5)$ & & $7.9(5.9)$ & $11.1(7.4)$ \\
Lexion & $6.8(7.7)$ & $13.8(18.1)$ & & $10.3(8.5)$ & $11.1(9.2)$ \\
Right rotation & $7.9(6.1)$ & $9.3(8.1)$ & & $5.9(3.6)$ & $9.7(8.7)$ \\
Left lateral flexion & $7.0(5.1)$ & $11.2(8.8)$ & & $8.0(5.6)$ & $9.2(7.1)$ \\
Right lateral flexion & $7.6(5.0)$ & $8.3(5.4)$ & & $8.3(6.0)$ & $9.8(6.2)$ \\
\hline
\end{tabular}

All data presented as mean (SD)

dependent variable and group, PD, effort level and groupxeffort were the independent variables, were applied. No group effect was found for test 1 or 2 . In both tests 1 and 2, there were highly significant $\mathrm{PD}$ and effort effects $(\mathrm{P}=0.0001)$. However, in test 1 , a significant interaction (group $\times$ effort) was observed $(\mathrm{P}=0.007$ ), namely, while performing under pain simulation, CDC patients reduced their CROM by $5.1^{\circ}$ more than did whiplash patients $(\mathrm{P}=0.04)$. In test 2 , the findings were similar, namely, CDC patients reduced their CROM by $3.9^{\circ}$ more than did whiplash patients, but the difference did not reach significance $(\mathrm{P}=0.12)$.

\section{Score compression}

The angular range-based ratios ([CROM in submaximal effort]/ [CROM in maximal effort]) relative to each of the PDs and in both testing sessions are presented in Table 2 . This ratio describes the extent to which patients reduced their CROM due to the imagined pain, and its complement to 100 represents the compression score. Whiplash patients were extremely consistent in compressing the CROM to the same extent in both tests. Furthermore, with the exception of extension where the compression was approximately $25 \%$, for all other PDs, the simulation of pain led to a compression of $12 \%$ to $15 \%$. CDC patients were less consistent. With the exception of left lateral flexion in which compression was $15 \%$ on average, the compression in all other PDs exceeded 25\%. A mixed effects model indicated a significant $\mathrm{PD}$ effect $(\mathrm{P}=0.05)$ and a significant $\mathrm{PD} \times$ group effect $(\mathrm{P}=0.04)$. Specifically, in all PDs, except extension and left lateral flexion, there was either a significant or borderline significant increase for the CDC group compared with whiplash group (in flexion 19\% $[\mathrm{P}=0.03]$, in right rotation $17 \%[\mathrm{P}=0.05]$, in left rotation $16 \%$ $[\mathrm{P}=0.06]$ and in right lateral flexion $16 \%[\mathrm{P}=0.05])$. No time effect (test 1 versus test 2 ) was noted.
TABLE 4

Coefficient of variation scores during maximal (max) and submaximal (sub) effort for the cervical degenerative changes group

\begin{tabular}{lccccc}
\hline \multirow{2}{*}{ Primary direction } & \multicolumn{2}{c}{ Test I (\%) } & & \multicolumn{2}{c}{ Test 2 (\%) } \\
\cline { 2 - 3 } \cline { 6 - 6 } & Max & Sub & & Max & Sub \\
\hline Extension & $11.1(10.1)$ & $12.1(12.2)$ & & $9.2(7.4)$ & $13.1(8.9)$ \\
Flexion & $7.7(5.5)$ & $17.7(14.8)$ & & $6.3(6.8)$ & $11.8(13.2)$ \\
Left rotation & $4.8(4.2)$ & $10.4(13.2)$ & & $5.7(5.7)$ & $9.5(9.6)$ \\
Right rotation & $6.2(4.8)$ & $10.9(9.5)$ & & $4.9(6.2)$ & $10.7(9.9)$ \\
Left lateral flexion & $6.0(4.8)$ & $8.3(5.3)$ & & $8.4(6.9)$ & $11.7(12.8)$ \\
Right lateral flexion & $5.3(3.3)$ & $8.6(7.6)$ & & $6.4(4.2)$ & $9.1(8.4)$ \\
\hline
\end{tabular}

All data presented as mean (SD)

The CROM-based coefficient of variation

In all but a handful of instances, the coefficient of variation $(\mathrm{CV})$ in the submaximal effort was larger than that of the maximal effort (Table 3 and 4). When all PD-based CVs from the whiplash group were combined into an average figure, this resulted in $7.89(3.67) \%$ and $10.25(4.85) \%$ for the maximal and submaximal efforts, respectively. The corresponding figures for the CDC group were $6.84(3.43) \%$ and $11.13(6.39) \%$, respectively. A mixed effects model revealed no group or testing session effects. However, the CVs of the submaximal effort were significantly higher than those calculated for the maximal effort ( $P=0.0001)$. A significant effect was also noted for the PD $(\mathrm{P}=0.0007)$ and for the interaction group $\times \mathrm{PD}(\mathrm{P}=0.04)$.

Deciding submaximal effort

A logistic model allowed the probability with which an individual whiplash patient could be judged as submaximizing their performance to be determined, assuming the cue for this performance was pain. The relationship is expressed by the following formula: $y=0.22+0.031 \mathrm{CVi}$, where $\mathrm{y}$ is the level of confidence and $\mathrm{CVi}$ is the individual average $\mathrm{CV}$ based on all PDs in the submaximal effort. For example, to state with a probability of $95 \%(0.95)$ that a whiplash patient is submaximizing their CROM, their $\mathrm{CVi}$ should be: $(0.95-0.22) / 0.031=23.5 \%$. For a $90 \%$ and $99 \%$ probability, the corresponding CVi scores would be $21.9 \%$ and $24.8 \%$, respectively. Of note, the highest maximal effort average $\mathrm{CVi}$ score in the present whiplash sample was $19.1 \%$, while the lowest was $2.9 \%$. In the pain simulation condition, a single whiplash patient exceeded the $99 \%$ probability and two exceeded the $95 \%$ probability.

\section{DISCUSSION}

A number of principal findings emerged from the present study. First, the two functional measures, pain and CROM, were not correlated. Second, the compression of CROM scores in the pain simulation condition were extremely consistent in the whiplash group, both in terms of the testing session and among all PDs, save extension. The same applied for the CDC group, although with slightly less rigor. Third, the two groups differed significantly in compressing the CROM. Fourth, while the CV scores relating to the simulation were significantly higher than their maximal counterparts, the overlap between the two levels of effort did not allow for an effective differentiation. However, based on the CVi scores, a logistic model yielded a decision rule regarding the acceptance or rejection of CROM performance. Different aspects of these findings deserve special attention. 
First, the lack of correlation between the level of pain reported by the patients and CROM is in general agreement with previous findings. Various studies (18-21) have strongly indicated that, although statistically significant, this relationship was fair and that as a result, a large proportion of the pain severity could not be identified by the CROM. Of note, an electromyograph study (22) of the sternocleidomastoid muscle indicated that many whiplash patients never reached the point in the range of motion where muscular activity rises steeply, thus, maintaining their cervical spine in the so-called 'neutral zone'. This behaviour, which is driven by existing pain or fear of pain, may be partly responsible for the low pain-CROM correlations. It should also be noted that while performing a CROM test, patients were instructed to reach the painful region but not to go beyond it. The subjective nature of this instruction may have further confounded this relationship.

The second major issue concerns the reduction in CROM under simulated pain and its stability over time, as well as the distinctive nature of CROM compression in whiplash versus CDC patients. Simulation under pain resulted in significant reductions in CROM in both groups. However, how should the significant differences in the compression ratios between the CDC (27\%) and whiplash (15\%) groups be interpreted? In particular, if the argument for the existence of an intentional submaximal effort among whiplash patients is correct, how could this be reconciled with a significantly lower compression of CROM compared with a group devoid of any monetary interest? Before offering an interpretation, it is worth noting that while an average reduction of CROM (as observed in the CDC group) could alter the rating of impairment, the average magnification of CROM restriction measured in whiplash patients may have only a marginal effect.

Thus, in attempting to explain the differences and their significance, it should first be emphasized that because the compressions were extremely stable over a period of days, the likelihood of a chance finding is very low. Second, examination of the compression of CROM in the whiplash group revealed that, with the exception of extension, motion in all PDs was uniformly reduced, albeit only moderately. The relatively large simulation-induced compression in the extension scores mirrors the comparatively higher reduction in this PD, which is characteristic of whiplash (23). Because extension is the movement most closely associated with the mechanism of whiplash injury, it stands to reason that fear of re-injury is the basis of its higher compression. Moreover, unlike the other PDs, extension of the neck can provoke the negative sensation of dizziness, thus, amplifying apprehension. In contrast, CDC patients did not single out extension as the most threatening $\mathrm{PD}$, a finding that supports the above explanation. It should also be noted that the instruction in the standard test was to continue moving the head until pain was encountered, without explicitly stating a level of pain that should have been reached before movement was stopped. Therefore, it is possible that patients in the whiplash group terminated movement at a relatively low level of pain and, hence, their 'motion reserve' during the simulation paradigm was larger, allowing for a smaller reduction in CROM. The fact that the flexion and lateral flexion (right and left) were reduced by the same extent may be explained by the role of the sternocleidomastoid muscle in moving the head in these PDs (22), although this issue requires further investigation.
Viewed from another perspective, it is noteworthy that CDC patients did not differ from their whiplash counterparts in terms of pain intensity (Table 1), although their global NDI score tended to be relatively higher, with five patients rating themselves as fully disabled. However, because the NDI's pain subscale is based on a momentary sensation, a higher general level of pain among CDC patients could not be ruled out. Thus, it is possible that the length of time since the onset of the symptoms (at least one year) and the frequency with which the symptoms may have worsened could create a more pronounced experience and appreciation of pain, eventually leading to a larger reduction in $\mathrm{CROM}$ on pain simulation. It is also possible that other ramifications of CDC, such as radiating pain, could contribute to an overall heightened sensitization. On the other hand, whiplash patients were less exposed to pain (six to 12 months), and their reported disability was generally lower. Thus, the general experience of pain could be more acute among CDC patients, limiting their 'motion reserve' during simulation and driving down their CROM. Further research is needed to support this argument .

In attempting to differentiate between maximal and submaximal effort, CV, a consistency parameter, was applied. With the exception of a single PD in test 1 , the submaximal effort-based CVs were consistently higher than the corresponding scores in the maximal effort (Table 3 ). However, relative to the average $\mathrm{CV}$ in maximal effort, the increase in the $\mathrm{CV}$ due to simulation was by approximately $30 \%$. In comparison, a rise of approximately $200 \%$ in the submaximal effort relative to the maximal effort has been revealed in normal subjects feigning whiplash injury (10). Thus, whereas CV effectively differentiated between maximal and submaximal effort in normal subjects, it was not sufficient in the present study for whiplash or CDC patients. For the whiplash group, this negative finding resulted from the relatively small compression of the CROM. In spite of that, a logistic model yielded a CVbased cut-off which allowed acceptance or rejection of claims made by whiplash patients regarding their limitation in CROM. This model, which operates on the individual level, is clearly sensitive to sample size and, hence, future research based on much higher patient numbers is expected to drive the cut-off scores down substantially.

\section{CONCLUSIONS}

The relatively small and stable compression of CROM under pain simulation supports the view that the likelihood that chronic whiplash patients are magnifying restriction of CROM using pain as a cue is very low.

\section{REFERENCES}

1. Spitzer WO, Skovron ML, Salmi LR, et al. Scientific monographof the Quebec Task Force on Whiplash-Associated Disorders: Redefining "whiplash" and its management. Spine 1995;20(8 Suppl):1S-73S. Erratum in: $1995 ; 20: 2372$.

2. Cassidy J, Carroll L, Cote P, Lemstra M, Berglund A, Nygren A. Effect of eliminating compensation for pain and suffering on the outcome of insurance claims for whiplash injury. N Engl J Med 2000;342:1179-86.

3. Castro WH, Meyer SJ, Becke ME, et al. No stress - no whiplash? prevalence of "whiplash" symptoms following exposure to a placebo rear-end collision. Int J Legal Med 2001;114:316-22.

4. Ferrari R, Schrader H. The late whiplash syndrome: A biopsychosocial approach. J Neurol Neurosurg Psychiat 2001;70:722-6. 
5. Freeman MD, Croft AC, Rossignol AM, Weaver DS, Reiser M. A review and methodologic critique of the literature refuting whiplash syndrome. Spine 1999;24:86-98.

6. Merskey H, Teasell RW. A troubling story: Insurance and medical research in Saskatchewan. Pain Res Manage 2002;7:65-7.

7. Scholten-Peeters GG, Verhagen AP, Bekkering GE, et al. Prognostic factors of whiplash-associated disorders: A systematic review of prospective cohort studies. Pain 2003;104:303-22.

8 Wallis BJ, Bogduk N. Faking a profile: Can naïve subjects simulate whiplash responses? Pain 1996;66:223-7.

9. Berger M, Lechner-Steinleitner S, Hoffmann F, Schonegger J. [Discrimination between pain-induced head movement disturbances after whiplash injuries and their simulation]. Schmerz 1998;12:400-5.

10. Dvir Z, Prushansky T, Peretz C. Maximal versus feigned active cervical motion in healthy patients: The coefficient of variation as an indicator of sincerity of effort. Spine 2001;26:1680-8.

11. Dvir Z, Penso-Zabludowski E. The effects of protocol and test situation on maximal vs. submaximal cervical motion: Medicolegal implications. Int J Legal Med 2003;117:350-5.

12. Kasch H, Bach FW, Jensen TS. Handicap after acute whiplash injury: A 1-year prospective study of risk factors. Neurology 2001;56:1637-43.

13. Cocciarella L, Andersson GBJ, eds. Guides to the Evaluation of Permanent Impairment, 5th edn. Chicago: American Medical Association Press, 2001:417-22.

14. Marras WS, Lewis KE, Ferguson SA, Parnianpour M. Impairment magnification during dynamic trunk motions. Spine 2000;25:587-95.
15. Dvir Z, Prushansky T. Reproducibility and instrument validity of a new ultrasonography-based system for measuring cervical spine kinematics. Clin Biomech 2000;15:658-64.

16. Vernon H, Mior S. The Neck Disability Index: A study of reliability and validity. J Manipulative Physiol Ther 1991;14:409-15.

17. Dvir Z, Werner V, Peretz C. The effect of measurement protocol on active cervical motion in healthy subjects. Physiother Res Int 2002;7:136-45.

18. Lee H, Nicholson LL, Adams RD. Cervical range of motion association with subclinical neck pain. Spine 2004:29:33-40.

19. Olson SL, O'Connor DP, Birmingham G, Broman P, Herrera L. Tender point sensitivity, range of motion, and perceived disability in subjects with neck pain. J Orthop Sports Phys Ther 2000;30:13-20.

20. Hagen KB, Harms-Ringdahl K, Enger NO, Hedenstad R, Morten H. Relationship between subjective neck disorders and cervical spine mobility and motion-related pain in male machine operators. Spine 1997;22:1501-7.

21. Kasch H, Stengaard-Pedersen K, Arendt-Nielsen L, Staehelin Jensen T. Headache, neck pain, and neck mobility after acute whiplash injury: A prospective study. Spine 2001;26:1246-51.

22. Klein GN, Mannion AF, Panjabi M, Dvorak J. Trapped in the neutral zone: Another symptom of whiplash-associated disorder? Eur Spine J 2001;10:141-8.

23. Dall'Alba PT, Sterling MM, Treleaven JM, Edwards SL, Jull GA. Cervical range of motion discriminates between asymptomatic persons and those with whiplash. Spine 2001;26:2090-4. 


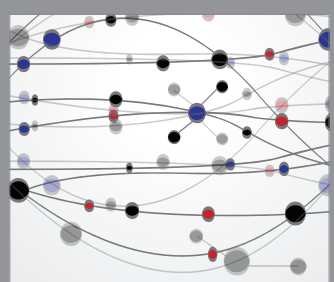

The Scientific World Journal
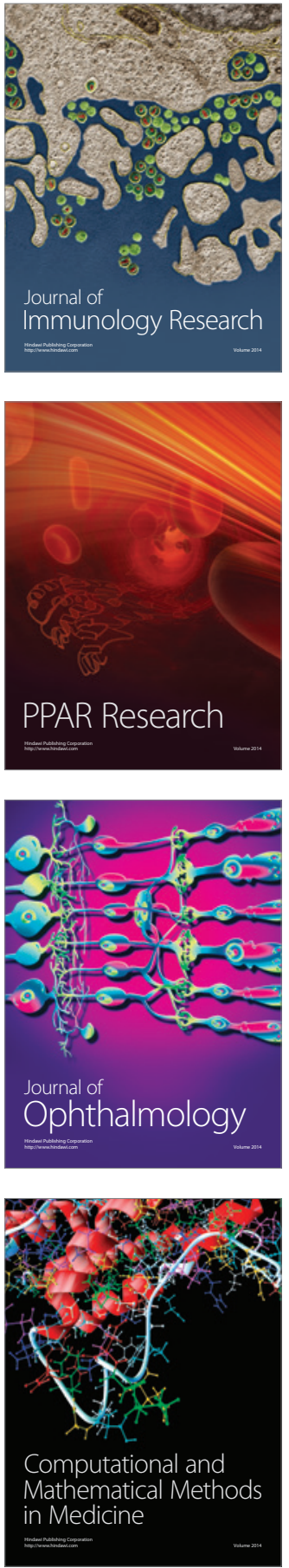

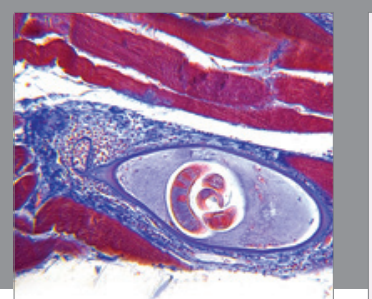

Gastroenterology Research and Practice

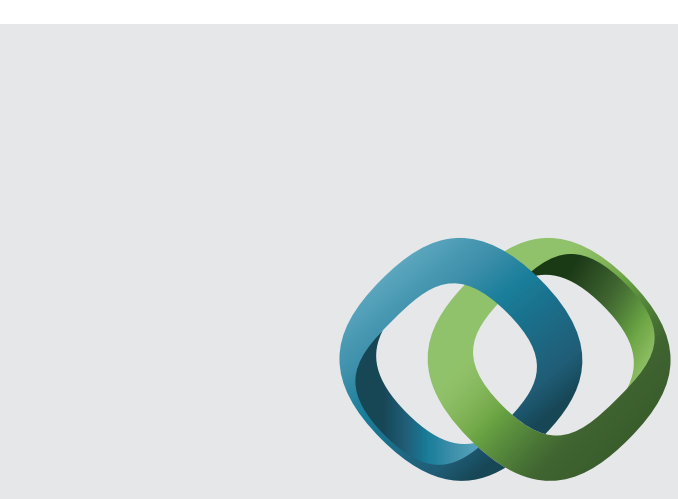

\section{Hindawi}

Submit your manuscripts at

http://www.hindawi.com
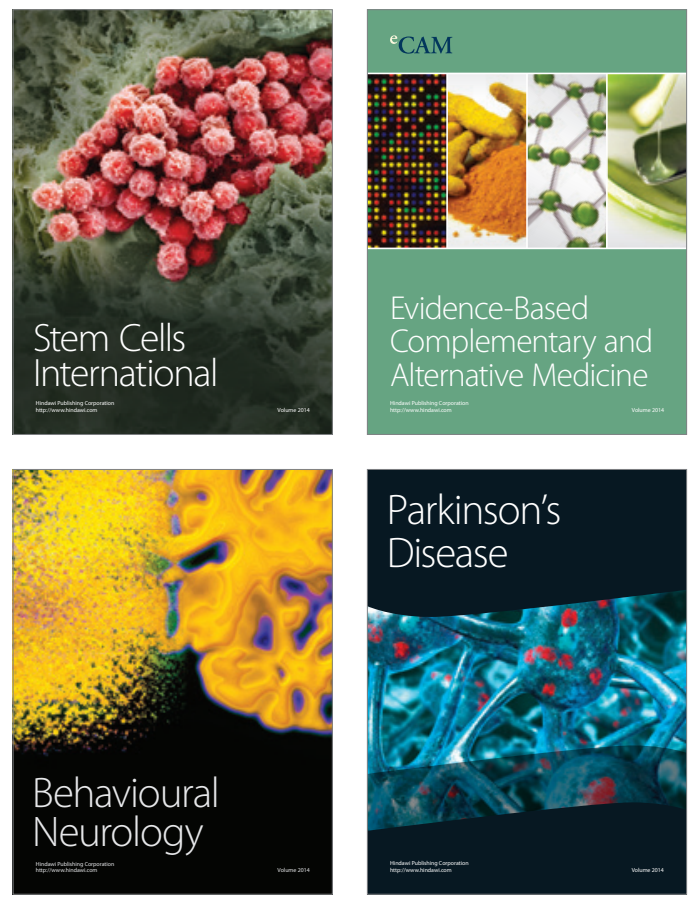
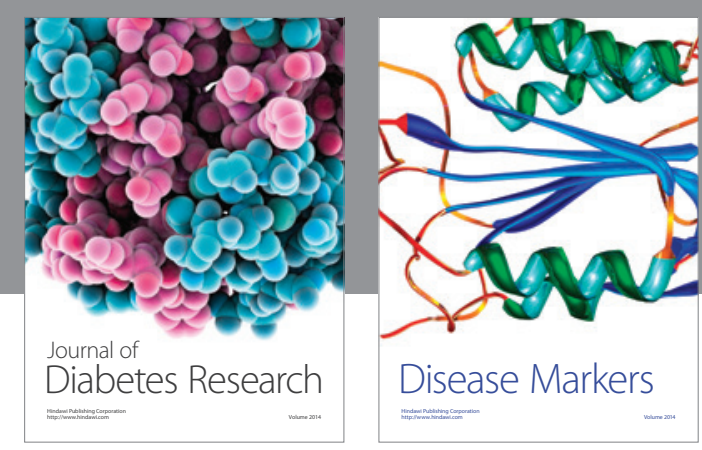

Disease Markers
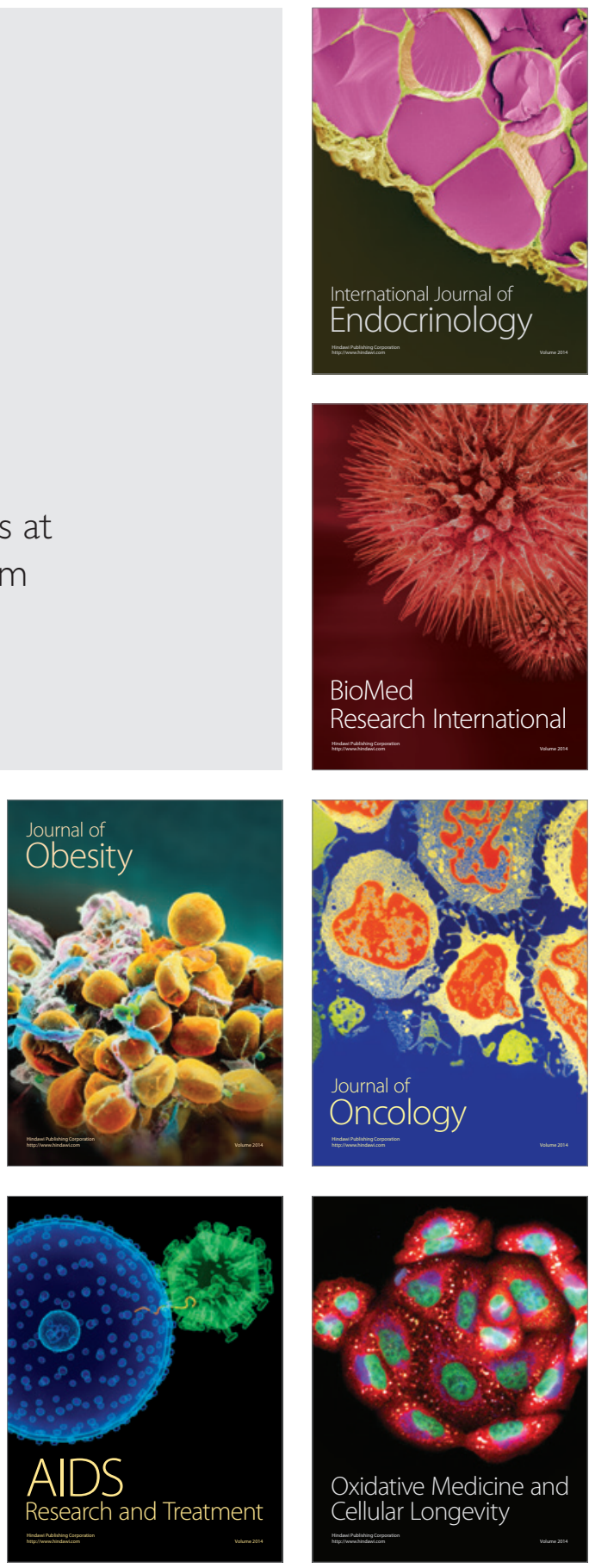